\title{
Imagens Técnicas e Distopias. A Sociedade Programada no Pensamento de Vilém Flusser
}

//I/I/I/I/I/I/I Milton Pelegrini

UNIP, PUC/SP 


\section{Resumo}

O presente artigo pretende encontrar um viés condutor que permita observar, no pensamento de Vilém Flusser, como as imagens técnicas, ou tecnoimagens, possuem uma intenção programática de levar a cabo a lógica do capital para articular consensos sociais sobre seus consumos. Como conseqüência pode-se perceber o desmantelamento de uma utopia e o surgimento de uma nova maneira de se vincular com o futuro, agora de um modo diferente, distópico, com base na programação totalitária das sociedades pelas exposições maciças de tecnoimagens.

\section{Palavras-chave}

Imagens Técnicas, Tecnoimagens, Distopia.

Abstract

This article intends to find a common thread that allows to see, in the Flusser's thought, how the technical images, or technoimages, have a programmatic intention to conduct the logic of capital to articulate social consensus on their consumption. As a result we can see the dismantling of a utopia and the emergence of a new way to link with the future, now in a different way, dystopian, based on programming of totalitarian societies by the massive exposures of technoimages.

\section{Key-words}

Technical Images, Technoimages, Dystopia. 
O mundo das imagens técnicas é um não lugar. $\mathrm{O}$ vazio e a imaterialidade constituintes das não coisas desse mundo são parte de uma estrutura tornada visível apenas superficialmente, e como tal, não tem raízes. A pesquisa de Vilém Flusser acerca do mundo das “coisas" e das "não coisas" (Ding und Unding) aponta para uma mudança na configuração do conjunto da sociedade a partir do advento das tecnoimagens. Pode-se observar nelas a força atraente de sua presença mediática, a onipotência de seu centro e sua capacidade de fabricação dos receptores e dos "funcionários" dessas imagens. Parece tratar-se de um tipo novo de reprogramação do imaginário coletivo, mas de um modo totalmente diferente. Enquanto as utopias eram projetos coletivos que guiavam líderes e estes conduziam as sociedades para dar curso às esperanças de um futuro capaz de absorver todas as contradições da vida em grupo e/ou eliminar o sofrimento e a barbárie humanos (como o caso da utopia das sociedades industriais), o atual universo das imagens técnicas tende a produzir cenários distópicos, onde o totalitarismo programado guiará as ações pela propagação desenfreada das exposições de imagens mediáticas. Dizia Flusser que sendo a multiplicabilidade automática a característica principal das tecnoimagens, a condução para esta distopia não seria exercida por uma autoridade pois "nas imagens técnicas todas as decisões são tomadas automaticamente", como resultantes de um consenso programado e fabricado em massa. Um frio diagnóstico sobre o fim de uma utopia e a imersão em novo projeto social com base nos ditames das entidades imateriais construídas para inundar o 
imaginário coletivo, ou seja, o mundo das imagens planificadas que torna-se hegemônico pela força da lógica do capital.

Considerando o entendimento de Vilém Flusser para definir a natureza funcional das tecnoimagens, pois são programáveis, podese supor que elas atuem sistematicamente no sentido de propagar um determinado tipo de logicidade, quase sempre com uma clara intenção de existência hegemônica. Assim, por toda parte as imagens técnicas surgem como entidades facilitadoras da compreensão provocando intencionalmente, como resultado, o convencimento coletivo.

A mídia é um agente concentrador da produção e propagação destas imagens técnicas, e pode incluir, em seu propósito, a fabricação de consensos, sejam eles fincados nos territórios movediços da memória passada, na história, ou nas vinculações com as memórias futuras, consolidadas coletivamente sob a nomenclatura de novos projetos para as sociedades.

Um notável exemplo dessa funcionalidade programática em larga escala é a observação da disputa eleitoral que ocorre periodicamente traduzida em imagens mediáticas pela Televisão (imagens audiovisuais), Jornais (imagens verbais-escritas), Rádio (imagens sonoras) e seus canais de distribuição em rede. Percebe-se que as imagens construídas propagam cenários de uma memória política pregressa da cena política que lastreia o presente, ao mesmo tempo em que planifica um futuro politicamente "desejável" para os candidatos (eles mesmos mais sintonizados, cada vez mais, com a mídia do que com a sociedade). Assim, candidatos e eleitores se constroem a partir dos modelos programados pelas tecnoimagens. Não é à toa que cresce o número de candidatos eleitos por sua própria imagem construída midiaticamente, tamanha é a força de atração imagética gerada pelos meios. São reflexos da mídia na construção das dinâmicas sociais em suas práxis políticas.

O papel das tecnoimagens no processo formador desses traços coletivos de apropriação da realidade é o objeto central da presente pesquisa, e para tanto, é preciso considerar a reunião dos fragmentos desta proto-tese, ou proto-teoria, que viria mais tarde consolidar Vilém Flusser como um pensador que incluiu a análise dos media, levando-se em conta elementos da cultura e incorporando a dimensão humana como elemento-chave para compreender como a lógica produtiva, o conceito de progresso, as maravilhas da industrialização, a lógica do consumo e a funcionalização do conhecimento 
escoaram pelos media, com um sentido único, crescente e cada vez mais veloz nos tecidos sociais.

A superficialidade das imagens técnicas, como observou Flusser em seu livro O Universo das Imagens Técnicas, traz implícita a lógica do imaterial, a lógica do capital como instrumento de submissão coletiva na imagem de um futuro a ser atingido pelo progresso tecnológico. Flusser chamava de "programas" que nos tornavam funcionários, ou funcionais, melhor dizendo, para manter a coerência com a idéia do funcionalismo dos meios de comunicação. Resulta, por isso, não ser estranho que os discursos na defesa do determinismo técnico caminhem lado a lado com a imaterialidade do mundo, e a expliquem por meio da ubiqüidade dos veículos de comunicação nos dias atuais.

Conceitos como "sociedade da informação" já deixaram de produzir olhares críticos para dar lugar a monolíticos entendimentos de que as redes de informação são as novas esferas públicas. Mas aqui é preciso demarcar uma diferença fundamental de entendimento. Espaços públicos são públicos porque congregam interesses públicos, e não é possível depreender que os interesses que movem a gestão tripartite das redes atuais sejam efetivamente públicos. Vejamos, as corporações que representam o setor das Telecomunicações, o setor da Computação e os Conglomerados de Mídia, construíram, no início dos anos de 1950, o cenário distópico que estamos perseguindo hoje.

O movimento dessas indústrias e o mercado construíram o ciberespaço (não lugar) das novas "esferas públicas" onde é possível observar como a lógica do capital impacta os grupos sociais de um modo determinante. É dessa imaterialidade das imagens, das ações simbólicas dos sinais que nascem essas novas sociedades industrializadas e suas perspectivas distópicas por meio da difusão maciça das imagens que reproduzem a lógica hegemônica do capital. Tudo é propagado como parte estratégica de novos e antigos modelos de negócio.

Algumas observações da existência desta lógica produzindo ou interferindo diretamente na cultura ocidental foram mostradas em um ensaio de 28 de outubro de 1961, no qual Flusser apontava a simbiose entre a cidade de Praga e o escritor Franz Kafka, autor que ainda foi capaz de refletir sobre o panorama de transformação social europeu, vislumbrando o espírito do tempo (Zeitgeist) no escritor tcheco. 
A autodepreciação, o nojo de si mesmo que é tema básico de Kafka é interpretada como um traço quase patológico da alma do autor, quando, na realidade, exprime uma disposição de uma cidade e civilização voltadas contra si mesmas, numa mistura de furor suicida e auto-erotismo. (FLUSSER, 28/10/1961)

Flusser a considerava como uma "cidade medieval industrializada", e afirmava no texto que Kafka "é o cantor de uma cidade e uma civilização que morreram, quase simultaneamente com ele”. São os primeiros diagnósticos que apontam para o sentido de um mundo industrializado que apostou todas as fichas na configuração de realidades nascidas desta lógica. As novas imagens do mundo estavam nascendo de um mundo de imagens produzidas para o consumo em alta escala, fossem elas de natureza político-ideológica, econômico-financeira, científico-industrial ou mesmo religiosas.

Essas imagens disseminadas pelos aparatos de mediação cumpriram uma dupla função no entendimento flusseriano. Primeiro, a de substituir a experiência do real pela representação de uma realidade, ela mesma tornada visível apenas como imagem, como superfície, e em segundo, pelo fato de decorrer dessa substituição a transformação do homem em espectador, colocando-o em oposição ao universo das realidades. "Um dos sintomas mais inquietantes da decadência da civilização tecnológica é a busca pela diversão", vaticinava Flusser no artigo publicado em 15 de julho de 1963.

Por 'universo', dizia o autor, entenda-se a "soma de todas as coisas vertidas em uma só coisa” e a recusa em verter as coisas em um universo, ou seja, a 'aversão', assumiu o formato de 'diversão' como modelo conceitual desta recusa em universalizar o mundo. Para Flusser, diversão é sinônimo de aversão do universo. Existem ainda desdobramentos conceituais que fluem da diversão para a diversificação, desta para a inversão e depois para a perversão. Pode-se depreender o caráter deste distanciamento do universo em nome da diversão, aliás, ela mesma um dos elementos constitutivos das tecnoimagens, produzidas para divertir. O papel do cinema na construção mediática da lógica do imaterial e de seu conseqüente distanciamento do mundo foi explicado no artigo:

O cinema é divertido por duas razões fundamentais: diverte a atenção daquilo que chamamos, normalmente, de "realidade", e converte 
o homem de participante em espectador. A primeira função do cinema é portanto tapar a "realidade", e a segunda é criar distância entre a pseudo-realidade assim produzida e a pessoa. Destrói, portanto, o universo de duas maneiras: racha-lhe a unidade (opondo a tela à "realidade"), e o afasta (pondo a nós, os espectadores, em oposição ao universo). O cinema é divertido porque destrói o universo. O universo se tornou insuportável na fase atual da civilização tecnológica, porque a sua universalidade consiste na transformação de todas as coisas em instrumentos. (FLUSSER, 15/6/1963)

E ampliava a argumentação, por si só precisa, mas angustiante:

O nosso universo é universo porque tudo nele é convertido em instrumento, inclusive o homem. Entretanto, este tipo de universalidade é de um tédio insuportável. O cinema, destruindo o universo dos instrumentos da maneira dupla acima esboçada, é divertido, porque aparentemente acaba com o tédio. Opõe ao mundo dos instrumentos um mundo de sombras aparentemente cheio de aventuras, e afasta o espectador para uma posição aparentemente "transcendente". Cria a aparência de uma transcendência do universo. Entretanto essas aparências enganam. O cinema longe de criar uma autêntica alternativa à universalidade instrumental, contribui para o alastramento da instrumentalização. E, longe de proporcionar uma autêntica transcendência, integra o homem ainda mais na engrenagem universal, transformando-o de participante em instrumento da indústria cinematográfica. O cinema é portanto uma destruição do universo apenas aparente. É uma forma inautêntica de aversão ao universo. Em conseqüência, não acaba com o tédio, mas o intensifica. O cinema não diversifica, nem inverte, nem perverte o universo, mas apenas diverte dentro do universo. O cinema é um fenômeno inautêntico e tedioso. (FLUSSER, 15/6/1963)

Nota-se aqui um esboço de articulação lógica para compreender os fenômenos mediáticos como agentes de disseminação das imagens técnicas estrategicamente expostas em favor do distanciamento, da imaterialidade do mundo, da superficialidade, do entretenimento, da configuração industrializante da produção e do consumo, da apropriação do tempo da experiência pela exposição "divertida" de uma experiência não vivida, mas representada. Uma proto-teoria 
das imagens técnicas que identifica na diversão uma aparência inofensiva, mas em cujo propósito reside o estabelecimento do consenso coletivo que a tradução do mundo está nas próprias imagens que os aparatos técnicos fazem da realidade.

Dizia o autor que da redução das tecnoimagens em um elemento fundamental chega-se ao 'ponto', tecnologicamente traduzível nos dias de hoje por 'pixel', e que para entender a verdadeira função das imagens técnicas deve-se compreender o conceito de ponto (ou de pixel): "o ponto é maneira geométrica de articular o nada", uma vez que "ponto" não possui dimensão e não ocupa espaço. Trata-se de se considerar o vazio que reside por detrás dessas imagens e sua função estratégica, operadora do consumo, dentro da lógica da imaterialidade que configura a lógica do capital, que por sua vez, define a lógica da produção que gera a lógica do consumo, que faz existir, finalmente, a materialidade do mundo através da imaterialidade das imagens. Um tipo específico de circularidade conceitual estabelecido midiaticamente pelas máquinas produtoras de imagens, gerando um fenômeno estudado por Norval Baitello Junior que recebeu o sugestivo nome de "Iconofagia", ou seja, um processo de devoração das imagens e/ou pelas imagens.

As implicações dessa dinâmica são gigantescas se considerarmos que esses vazios, ou tecnoimagens, circulam midiaticamente como estratégias de controle de atenção. Daí sua conseqüente apropriação do tempo de vida de um modo perverso, quase sempre, pela diversão, pelo entretenimento, como apontava Flusser. Nesse sentido, o atual estágio da civilização se configura pelo consumo exacerbado de imagens que se propõem ocupar o espaço da realidade, conforme explica Baitello Junior.

A era da Iconofagia começa a se delinear quando "ao consumir imagens, já não as consumimos por sua função janela (Kamper), mas pela sua função biombo (Flusser)". Ao devorar imagens anteriores, toda imagem se presta a ser devorada pelas imagens futuras, impedindo-nos de alcançar-lhes um fundamento, um alicerce sustentável de significação. O excesso de visibilidade cega a percepção do homem para o corpo real e o leva a assumir um corpo virtual que prima pela distancia e pela assepsia do contato com o real; uma realidade demasiadamente humana para um mundo tecnologicamente em superação constante. (BAITELLO J., 2005, p.25) 
A funcionalidade das imagens conforme explicitada por Norval Baitello Jr. se insere no contexto do prognóstico de Flusser sobre a sociedade programada. As imagens podem mediar o homem com o mundo, como uma janela (Kamper), mas, pelo esvaziamento de suas características em favor da superficialidade, da desconexão com o mundo, da autorreferencialidade, elas, sobretudo as tecnoimagens, transformam-se num biombo que pretende ser, ele mesmo, o mundo a ser vivido. Talvez seja a explicação para o fato de que os meios de comunicação se transformaram em agentes de sua própria existência. Assim, os investimentos para superar constantemente o tédio depois que passamos a acreditar nas imagens desse mundo se manifestam pela evolução tecnológica dos aparatos, na instrumentalização política e econômica das tecnologias de mediação, na velocidade do processamento e das conexões. Passamos a considerar a "imagem" e a "coisa" como uma única entidade perceptível, e dela decorre nossa compreensão de mundo. Flusser comentava sobre isso em um artigo dedicado a refletir sobre como perdemos a capacidade de nos espantar com o mundo.

O conjunto das coisas é a Natureza, e a transformação das coisas em instrumentos equivale à domesticação da Natureza, portanto ao seu aniquilamento. A Natureza, tendo deixado de ser espantosa, deixou de ser a Natureza. É verdade que a atenção do pensamento ocidental se terá dirigido contra a Natureza, e o resultado desta atenção é o aniquilamento da Natureza... ...Tendo sido a Natureza transformada de espanto em tédio, estamos inclinados a concluir que o mundo inteiro se tornou tedioso, e sentimos existencialmente esse tédio absoluto... (FLUSSER, 25/4/1964)

Delineia-se o surgimento da aparente e inofensiva estratégia da diversão que se fundamenta e se concretiza na lógica da reprodutibilidade técnica das imagens. O rompimento desse sentimento de "tédio absoluto" passa necessariamente do "mundo das coisas" para o "mundo das não coisas", outra reflexão de Flusser para tornar visível a lógica da imaterialidade que estrutura as tecnoimagens. Segundo afirmava no livro "The Shape of Things", editado em 1999, o mundo das coisas (hardware) perde gradativamente valor de mercado em favor do mundo das não-coisas (software), que ao contrário custa cada vez mais. Dizia que "nosso interesse existencial se transforma, a 
olhos vistos, das coisas para as informações", e que "ao mesmo tempo, uma parte cada vez maior da sociedade se ocupa de fabricar informações, dos serviços, de administrar, de programar, e cada vez menos se ocupam de fabricar coisas".

Retomando a segunda função das tecnoimagens tratadas no início deste artigo, a transformação do homem em espectador corresponde em atribuir-lhe uma função, transformá-lo em funcionário que faz o aparato funcionar. Flusser usa como exemplo, em seu artigo "Do Funcionário", publicado curiosamente em $1^{\circ}$ de maio de 1965 (Dia do Trabalho), que o funcionário movimenta-se e age em função do aparelho, e para o funcionário perfeito, o aparelho tem completa autonomia, e o funcionário tem a sua função estabelecida. "Todo funcionário é uma propriedade, um atributo do aparelho. O funcionário não tem propriedade, ele é propriedade. Como a propriedade nunca se confunde com a substância, o funcionário não se confunde com o aparelho", advertia. 'Trabalhador' e 'Funcionário' são conceitos operacionais distintos para a lógica do capital e vivem em mundos distintos, o primeiro no mundo do hardware e o segundo no mundo do software, na acepção de Flusser.

As reflexões trazidas por Vilém Flusser acerca das ciências da comunicação são importantes e mesmo fundamentais, desde que se pretenda compreender os fenômenos mediáticos como estratégias funcionalizantes da lógica do mercado que começa na produção das tecnoimagens, passa pelo consumo, ou pela produção do consumidor, do usuário, do espectador, ou do telespectador, todos vistos como funcionários, eles mesmos transformados em imagens técnicas e condenados a se representarem no mundo tedioso, mas de um modo divertido.

\section{Bibliografia}

ANDERS, Günther. 1956. La formación de las necesidades.

Título original: Die Prägung der Bedürfnisse

( 21 de Die Antiquiertheit des Menschen, Munich).

BAITELLO JR., Norval. 2005. A era da iconofagia. Ensaios de comunicação e cultura. S. Paulo: Hacker. 
BELTING, Hans. 2007. Antropología de la Imagen.

Madrid: Editorial Katz.

BENJAMIN, Walter. 1973. "La obra de arte en la época de su reproductibilidad técnica", in Discursos Interrumpidos I.

Madrid: Taurus Ediciones.

FLUSSER, Vilém. 1985. Filosofia da Caixa Preta. Ensaios para uma futura filosofia da fotografia. São Paulo: Hucitec.

FLUSSER, Vilém. 2008. O universo das imagens técnicas. Elogio da superficialidade. São Paulo: Anablumme.

FLUSSER, Vilém. La sociedad alfanumérica. In: Vilém Flusser y la crisis actual de la cultura (Dr. phil.) Breno Onetto (tradución)Instituto de Filosofía y Estudios Educacionales Escuela de Artes Visuales - Universidad Austral de Chile.

FLUSSER, Vilém. Da Diversão. In Suplemento Literário do Jornal O Estado de São Paulo. Publicado em 15 de junho de 1963.

FLUSSER, Vilém. Do Funcionário. In Suplemento Literário do Jornal O Estado de São Paulo. Publicado em $1^{\circ}$ de maio de 1965 .

FLUSSER, Vilém. Em Louvor do Espanto. In Suplemento Literário do Jornal O Estado de São Paulo. Publicado em 25 de abril de 1964.

FLUSSER, Vilém. Praga, a cidade de Kafka. In Suplemento Literário do Jornal O Estado de São Paulo. Publicado em 28 de outubro de 1961.

NIEZSTCHE, Friedrich W. 2003. A gaia ciência. São Paulo: Martin Claret editora.

OSTHOFF, Simone. 2007. Philosophizing in Translation: Vilém Flusser's Brazilian Writings of the 196os.

Delivered at re:place 2007 the Second International Conference on the Histories of Media, Art, Science, and Technology. Berlin, Germany, November 15-18.

PELEGRINI, Milton. 2008. Tecnologia e Mídia. O roubo do presente e a construção do futuro nos grupos sociais. São José do Rio Preto: Bluecom.

SCHOPENHAUER, Arthur. O mundo como vontade e representação. Vol. IV. Edição Acrópolis, Disponível em: http://www.ebooksbrasil.org/REB/ representacao4.br (2 de ago. 2009). 